\title{
DIFERENCIAS TERMINOLÓGICAS ENTRE EL ALEMÁN Y EL ESPAÑOL EN EL ÁMBITO LABORAL. EL CASO DE PRESTACIONES, PERMISOS Y SUBSIDIOS FAMILIARES
}

\author{
https://dx.doi.org/10.12795/futhark.2014.i9.09 \\ Ana Ledesma Claros \\ Universidad de Málaga \\ ana_st03@hotmail.com \\ María-José Varela Salinas \\ Universidad de Málaga \\ mjvs@uma.es
}

\begin{abstract}
The reasons that have led us to choose this topic are diverse. On the one hand, we start from the premise of a personal interest on knowing the German system of laws in the field of the benefits, leaves and subsidies in the work sphere. We do this in order to have a view on the German cultural reality that can help us to approach specialized texts in a more effective way. On the other hand, once we have gathered this knowledge, we can extract a great deal of terms that can be used as a consultation tool in legal and sworn translation. Finally, through the terminology extraction that we have got by analysing the legal texts, we aim to provide the translator with a glossary that helps him to face the challenges that can come from the language combination DE-SP.
\end{abstract}


Key words: equal treatment; working conditions of pregnant women; benefits and parental leave; family subsidies; balance between work life and family life.

Resumen: Son varias las razones que nos han llevado a profundizar en la investigación sobre el tema propuesto. En primer lugar, partimos del interés personal por el conocimiento del sistema legislativo alemán en el campo de las prestaciones, permisos y subsidios en el ámbito laboral a fin de adquirir una panorámica de la realidad cultural alemana que nos sea útil a la hora de abordar textos especializados. En segundo lugar, a partir del conocimiento de estos conceptos, podemos extraer una gran cantidad de términos que nos pueden servir como referente de consulta en las traducciones jurídicas y juradas. Por último, el fin de esta extracción terminológica que surge del análisis de los textos legales es elaborar una base terminologica que ayude al traductor a afrontar las dificultades que puedan derivarse de esta temática en la combinación lingüística DE-ES.

Palabras clave: igualdad de trato; condiciones laborales de la mujer embarazada; prestaciones y permisos parentales; subsidios familiares; conciliación entre la vida laboral y la vida familiar.

\section{INTRODUCCIÓN}

En el presente trabajo se lleva a cabo una recopilación de la terminología básica sobre prestaciones, permisos y subsidios familiares en el ámbito laboral en Alemania. La razón de que se hayan escogido estos tres conceptos como núcleo del trabajo se debe al interés que ofrecen para el campo de la traducción especializada DEES, ya que están relacionados con términos que no tienen equivalente terminológico total en español o que no poseen correspondencia en la cultura meta por tratarse de conceptos intrínsecamente relacionados con la cultura alemana. A ello hay que añadir que se ofrece una recopilación terminológica en una combinación lingüística (alemánespañol) en la que hay una gran escasez de recursos lexicográficos especializados.

La primera parte está dedicada al análisis de varias leyes alemanas que tratan no solo de prestaciones, permisos y subsidios familiares, sino también de cuestiones como la igualdad de trato de mujeres y 
hombres o la protección de la mujer embarazada en el ámbito laboral. La razon de que se hayan escogido estas leyes en particular es que en todas ellas encontramos elementos que hacen referencia a los permisos parentales, a las prestaciones familiares $\mathrm{y}$ a los subsidios por hijos.

A continuación, en la segunda parte del trabajo, nos centramos en el concepto de conciliación entre la vida laboral y la vida familiar en Alemania, intrínsecamente relacionado con el avance y la mejora de las prestaciones y de los permisos parentales. Por último, pasamos al plano europeo y analizamos algunas directivas relacionadas desde un punto de vista temático. La pertinencia de incluir en este trabajo este apartado sobre la legislación europea reside en que su transposición a la normativa de cada estado miembro de la Unión Europea es obligatoria.

Es necesario señalar que la dirección del este trabajo es DE-ES, por lo que en todas las partes del mismo se utiliza textos en alemán (en el caso del punto sobre las directivas europeas, se toma como referente la traducción al alemán de los textos originalmente redactados en inglés). Puesto que los textos legislativos exigen un alto nivel de precisión en la traducción, con el objetivo de ajustar al máximo su adecuación se consultaron dos fuentes terminológicas y documentales de la Unión Europea (Eur-Lex e IATE) para la extracción y confrontación terminológicas.

El análisis que se lleva a cabo en este trabajo se basa en la estructura propuesta por Alberto Arufe Varela en la obra La igualdad de mujeres y hombres en Alemania. Estudio comparado de la legislación alemana con la legislación española y traducción castellana (2008). En esta obra, el autor opta por incluir entre corchetes no solo los nombres de las leyes alemanas que analiza, sino también términos, colocaciones y nombres de organismos. Este tipo de estructura permite al lector confrontar la traducción al español del término en alemán de una forma cómoda y rápida. Además, en el caso de nuestro trabajo, el empleo de esta estructura permite observar una gran cantidad de términos en un reducido espacio textual. 


\section{PRESTACIONES, PERMISOS Y SUBSIDIOS EN EL ÁMBITO LABORAL}

Antes de adentramos en el análisis de los textos legales, estimamos conveniente presentar una panorámica tanto de España como de Alemania en lo que a leyes relacionadas con prestaciones, permisos y subsidios en el ámbito laboral se refiere. Esta panorámica abarcará la clasificación que se ha mencionado anteriormente, a saber: partirá de las leyes referentes a la igualdad de trato, pasará a continuación por las de protección de la mujer embarazada y de la madre en el trabajo y abordará finalmente las que se centran en las prestaciones, permisos y subsidios en el ámbito laboral. Por último, se hará referencia a la importancia del concepto de conciliación entre la vida laboral y la vida familiar tanto en Alemania como en España.

\subsection{EL CASO DE ESPAÑA}

En materia legislativa española sobre la igualdad de trato entre hombres y mujeres, cabe destacar la Ley Orgánica 3/2007, de 22 de marzo, para la igualdad efectiva de mujeres y hombres. En esta ley se defiende la igualdad de trato y de oportunidades en el ámbito laboral y se persigue el objetivo de garantizar la igualdad entre mujeres y hombres en el acceso al empleo. Para ello, se plantea un programa de mejoras en la empleabilidad de las mujeres y se propone fomentar los cursos de formación sobre la igualdad de trato y oportunidades entre mujeres y hombres. Asimismo, se establecen las condiciones del permiso de maternidad y, como novedad, el reconocimiento a los padres del derecho a un permiso y a una prestación por paternidad. A este respecto, cabe destacar que en España los padres tienen derecho a disfrutar de 15 dias de baja por el nacimiento, acogimiento o adopción de un hijo desde 2007.

A diferencia del caso de Alemania, que veremos a continuación, en España no existe una ley concreta para la protección de la mujer embarazada o de la madre en el trabajo, sino que se hace referencia a dicha protección en varias leyes. Por ejemplo, en la Ley Orgánica $3 / 2007$ se incluye un apartado sobre la protección de la mujer en 
situación de embarazo, parto y posparto. Asimismo, tanto en la Ley $39 / 1999$ como en la Ley 31/1995 se incluyen varios apartados dedicados a la protección de la maternidad, en los que se establecen las medidas de seguridad para la protección de la salud de la mujer embarazada o en periodo de lactancia. En ambas leyes se contempla que la mujer embarazada cambie de puesto de trabajo de forma temporal si el que desempeña supone un riesgo para su salud o para la del feto, sin que eso afecte a su retribución.

Estas leyes sobre la protección de la maternidad están relacionadas con el Real Decreto 295/2009, de 6 de marzo, por el que se regulan las prestaciones económicas del sistema de la Seguridad Social por maternidad, paternidad, riesgo durante el embarazo y riesgo durante la lactancia natural. En este documento se establecen prestaciones por riesgo durante el embarazo o durante la lactancia natural, por maternidad y por paternidad. Respecto a las excedencias para el cuidado de hijos, en la Ley 4/1995, de 23 de marzo, de regulación del permiso parental y por maternidad se establece que el periodo de excedencia no puede superar los tres años.

Respecto a los subsidios y ayudas por hijos a cargo, en España no existen unas leyes determinadas que se ocupen de este tipo de prestación familiar, sino que aparecen directamente reflejadas en la página de la Seguridad Social ${ }^{1}$. En el caso de la prestación económica por hijo o menor acogido a cargo, el importe que se percibe por cada hijo (hasta los 18 años), es de $24,25 €$ mensuales $^{2}$. No obstante, solo puede percibirse esta ayuda si los ingresos del beneficiario no superan el umbral de los $11519,16 €$ anuales, a excepción de los casos en los que el hijo tenga una discapacidad igual o superior al $33 \%$, al $65 \%$ o al $75 \%$, en cuyo caso, la cuantía pasaría a ser de $250,00 €$ trimestrales, $365,90 €$ mensuales o $548,90 €$ mensuales, respectivamente. Para las familias numerosas con un mínimo de tres hijos a cargo, se prevé una asignación íntegra anual de 1000 euros siempre y cuando sus ingresos anuales no superen los 17.337,05€. Asimismo, para el caso de partos y de adopciones múltiples (dos o más hijos), se concede a los padres un

\footnotetext{
'http://www.segsocial.es/Internet_1/Trabajadores/PrestacionesPension10935/Pr estacionesfamilia10967/Prestacioneconomica27924/Cuantias/index.htm ${ }^{2}$ Las cantidades mencionadas en este trabajo son válidas para el año 2014.
} 
pago único que es de ocho veces el salario interprofesional y oscila para 2014 entre los 2.581,20 y los 7.743,60 euros, dependiendo del número de hijos. ${ }^{3}$

Si bien la existencia de todos estos textos legislativos ha ayudado a mejorar las condiciones de igualdad, de protección de la maternidad y de mejora de las prestaciones familiares en el ámbito laboral en nuestro pais, lo cierto es que siguen siendo insuficiente y escasas, si se comparan con otros países de la Unión Europea como Alemania, Austria, Dinamarca o Suecia4.

A pesar de estas desigualdades, cabe destacar que el permiso por maternidad de 16 semanas de España cumple con el mínimo previsto por la Unión Europea (14 semanas) y supera el de otros países como Alemania (14 semanas) o Bélgica (15 semanas). Austria, Luxemburgo, Letonia y Francia, entre otros, también contemplan un periodo de 16 semanas para este permiso.

\subsection{EL CASO DE ALEMANIA}

El sistema social de Alemania difiere en muchos puntos del español, no solo por las diferentes situaciones económicas de cada país, sino también por las características culturales y sociales de cada uno de ellos.

Como ya se ha mencionado anteriormente, en Alemania existe un gran número de leyes que amparan a la mujer en el ámbito laboral. Destacan porque son leyes redactadas exclusivamente para definir qué condiciones debe tener la situación laboral de la mujer embarazada y de la madre, como es el caso de la Mutterschutzgesetz [Ley de protección de la maternidad] o del Verordnung zum Schutze der Mütter am Arbeitsplatz [Decreto sobre la protección de la madre en el lugar de trabajo].

\footnotetext{
${ }^{3}$ V. Ministerio de Sanidad, Servicios Sociales e Igualdad: Guía de ayudas sociales para las familias. 2014. Madrid.

4 Cf. Informe "Políticas de apoyo a la maternidad, breve estudio comparativo en paises de la UE"
} 
Respecto a la igualdad de trato, cabe señalar que las leyes alemanas comparten muchos puntos con las españolas y con las de otros países europeos, ya que muchas de las directivas de las que parten son emitidas por la propia Unión Europea. Las leyes alemanas sobre igualdad más importantes son la Bundesgleichstellungsgesetz [Ley federal de igualdad] y la Allgemeines Gleichbehandlungsgesetz [Ley federal sobre la igualdad de trato].

A diferencia de las similitudes que existen en el terreno de la igualdad, las leyes alemanas referentes a los subsidios por hijos a cargo y a las ayudas familiares no tienen ninguna correspondencia en la legislación española. En este trabajo analizaremos las dos leyes más importantes a este respecto: la Bundeselterngeld- und Elternzeitgesetz [Ley federal sobre prestaciones y permisos parentales] y la Bundeskindergeldgesetz [Ley federal sobre subsidios familiares].

\section{CLASIFICACIÓN DE LOS TEXTOS LEGISLATIVOS}

A fin de abarcar una panorámica lo suficientemente amplia del tema, hemos decidido analizar una muestra de textos legislativos alemanes (leyes, decretos y directivas) que tratan sobre diversos aspectos necesarios para comprender el entramado del sistema de permisos, prestaciones y subsidios en el ámbito laboral en Alemania. Así, en primer lugar hemos agrupado las leyes que tratan sobre la igualdad de oportunidades entre el hombre y la mujer y sobre la igualdad de trato en el ámbito laboral. En este grupo, analizamos dos leyes: la Bundesgleichstellungsgesetz [Ley federal de igualdad] y la Allgemeines Gleichbehandlungsgesetz [Ley federal sobre la igualdad de trato]. A continuación, pasamos a analizar los textos legislativos que tratan sobre la protección de la mujer embarazada en el lugar de trabajo y sobre las condiciones laborales de la madre. Dentro de este grupo, destacamos dos textos: la Mutterschutzgesetz [Ley de protección de la maternidad] y el Verordnung zum Schutze der Mütter am Arbeitsplatz [Decreto sobre la protección de la madre en el lugar de trabajo]. 
Para concluir la clasificación, dedicamos un apartado a las leyes en las que se detallan las condiciones de las prestaciones familiares, los permisos parentales y los subsidios por hijo a cargo en Alemania. En este apartado analizamos dos leyes: la Bundeselterngeld- und Eltemzeitgesetz [Ley federal sobre prestaciones y permisos parentales] y la Bundeskindergeldgesetz [Ley federal sobre subsidios familiares].

A partir del análisis de estos textos legislativos alemanes, redactaremos una detallada explicación de cada uno de ellos, al tiempo que incluimos los terminos originales entre corchetes a fin de que el lector tenga a disposición una comparativa terminologica dentro del mismo texto.

\subsection{LEYES LABORALES SOBRE LA IGUALDAD DE SEXOS $Y$ LA IGUALDAD DE TRATO EN EL ÁMBITO LABORAL}

\subsubsection{BUNDESGLEICHSTELLUNGSGESETZ [LEY FEDERAL DE IGUALDAD]}

La Bundesgleichstellungsgesetz («BGleigG») de forma abreviada en alemán), del 30 de noviembre de 2011, tiene entre sus objetivos principales promover la reducción de las desventajas laborales de las mujeres y la mejora de la conciliación entre la vida laboral y la vida familiar de mujeres y hombres.

El ámbito de aplicación de esta ley es la Administración Federal [Bundesvervaltung] de toda la República Federal de Alemania. Dentro de esta clasificación, se aplica, en concreto, a empresarios y a trabajadores del Estado, a cargos públicos o judiciales y a jueces.

Respecto a los aspectos de la ley que hacen referencia específicamente a las mujeres, cabe destacar los siguientes:

- Se considera que las mujeres están poco representadas [unterrepräsentiert] si en alguna de las áreas de la Administración la proporción de mujeres [Frauenanteil] es inferior al $50 \%$.

- La Administración Federal no puede sacar a concurso 
puestos de trabajo dirigidos específicamente solo a hombres o a mujeres. No obstante, si el número de mujeres de un área determinada tiene poca representación, ésta puede ofertar un puesto de trabajo en el que la selección de mujeres se vea favorecida para que la cifra de trabajadores y de trabajadoras esté igualada.

o En las entrevistas para puestos de trabajo en los que las mujeres están poco representadas, se debe realizar la entrevista al mismo número de mujeres y hombres, siempre y cuando haya suficientes solicitudes por parte de ambos sexos.

- Los comités de selección [Auswahlkommissionen] deben estar compuestos por hombres y mujeres a partes iguales.

- Si las mujeres están poco representadas en un área determinada, debe favorecerse su promoción profesional [beruflicher Aufstieg].

\subsubsection{ALLGEMEINES GLEICHBEHANDLUNGSGESETZ [LEY FEDERAL SOBRE LA IGUALDAD DE TRATO]}

La Allgemeines Gleichbehandlungsgesetz ("AGG» de forma abreviada en alemán), del.14 de agosto de 2006, tiene como objetivo acabar con la desigualdad por raza, origen étnico, sexo, religión, etc. Esta ley se aplica a toda discriminación que se dé en el ámbito laboral (por ejemplo, en criterios de selección para un puesto de trabajo, en las condiciones de trabajo, en el salario, etc.). Entre los aspectos de la ley referentes a las mujeres, cabe destacar el siguiente:

- Se considera que existe discriminación directa por razón de sexo [unmittelbare Benachteiligung wegen des Geschlechts] cuando se trata de manera menos favorable a una mujer por embarazo o por maternidad. 


\subsection{LEYES LABORALES SOBRE LA PROTECCIÓN Y LAS CONDICIONES DE TRABAJO DE LA MUJER EMBARAZADA YDE LA MADRE}

\subsubsection{MUTTERSCHUTZGESETZ [LEY DE PROTECCIONN DE LA MATERNIDAD]}

La Mutterschutzgesetz («MuSchG» de forma abreviada en alemán) es una de las leyes más importantes respecto a la legislación laboral de las mujeres. Fue aprobada en 1952, pero desde entonces ha sufrido dos importantes modificaciones en el 2002 y en el 2012.

Puesto que en esta ley se examinan diferentes aspectos de la situación laboral de la mujer embarazada y de la madre en periodo de lactancia, a continuación analizaremos de forma pormenorizada cada uno de los párrafos que la componen.

PRIMER PÁRRAFO: DISPOSICIONES GENERALES [ALLGEMEINE VORSCHRIFTEN]

En este párrafo se establece que la ley es aplicable a todas las mujeres que tengan un contrato laboral [in einem Arbeitsverhältnis stehen] o que trabajen a domicilio [Heimarbeit] de forma continuada [am Stück arbeiten].

Quien contrate a una mujer embarazada [werdende Mutter] o en período de lactancia [stillende Mutter] debe tomar las precauciones y medidas necesarias (por ejemplo, en la instalación de máquinas, aparatos y herramientas) para proteger la vida y la salud de la trabajadora.

Igualmente, la mujer embarazada o en período de lactancia que deba estar permanentemente de pie 0 andando debe disponer de un asiento [Sitzgelegenheit] para poder descansar. También en el caso de que la trabajadora permanezca demasiado tiempo sentada se le debe ofrecer la posibilidad de hacer pequeños descansos durante el trabajo [Unterbrechungen der Arbeit]. 


\section{SEGUNDO PÁRRAFO: PROHIBICION DE EMPLEO [BESCHÄFTIGUNGSVERBOT]}

Está prohibido contratar a una mujer embarazada si mediante un certificado médico [nach ärztlichem Zeugnis] se establece que la continuación de su actividad profesional [Erwerbstätigkeit] puede amenazar su vida o salud o la de su hijo.

En Alemania, a las mujeres embarazadas no se les permite trabajar en las seis semanas previas al parto [Entbindung] a menos que éstas declaren su conformidad de forma explícita a trabajar [sich zur Arbeitsleistung bereit erklären]. En cualquier caso, las trabajadoras pueden revocar este compromiso en cualquier momento. Asimismo, no se les permite realizar trabajos físicos pesados [schwere körperliche Arbeit] ni desempeñar un trabajo en el que puedan exponerse a los efectos de sustancias nocivas [gesundheitsgefährdende Stoffen], rayos, polvo, gases o vapores, etc. Tampoco deben desempeñar ninguna actividad laboral que, particularmente durante el embarazo, pueda llevarla a contraer alguna enfermedad profesional [Berufskrankheit] que implique un alto riesgo para ella o para el feto [Leibesfrucht].

Además, se contempla la prohibición de dar empleo a mujeres embarazadas si el trabajo es a destajo [Akkordarbeit] y, por lo tanto, la retribución depende de la intensidad del ritmo de trabajo [Arbeitstempo] (por ejemplo, un trabajo en cadena con un ritmo preestablecido). No obstante, el órgano de control correspondiente [Aufsichtsbehörde] puede hacer excepciones a este respecto si el tipo de trabajo y su ritmo no ponen en peligro la salud de la madre ni del hijo.

Por otra parte, en este párrafo se especifica que la mujer embarazada tiene la obligación de comunicar [Mitteilungspflicht] al empresario su embarazo en cuanto lo sepa, al igual que debe comunicarle el día en el que se produce el parto. Además, el empresario puede requerir que la mujer presente el certificado de un médico o de una comadrona [Hebamme]. El coste de la expedición de estos certificados corre a cuenta del empresario.

La prohibición de empleo se sigue manteniendo hasta ocho semanas después del parto. En el caso de partos prematuros [Frühgeburten] o de partos múltiples [Mehrlingsgeburten], la madre no 
puede trabajar hasta pasadas doce semanas. Posteriormente, tras la reincorporación al trabajo, las trabajadoras en periodo de lactancia disponen de una hora dentro de la jornada laboral para dar el pecho a su hijo. Si trabaja más de ocho horas, puede darle el pecho al niño [Stillzeit] dos veces durante 45 minutos o, en el caso de que no disponga de un lugar cercano donde dárselo [Stillgelegenheit], dispone de hasta 90 minutos. El trabajo se considerará continuo siempre y cuando la trabajadora no se tome descansos [Ruhepausen] de más de dos horas. El órgano de control puede definir en determinados casos el número, el lugar y la duración de las pausas para la lactancia y puede llegar a ordenar la instalación de salas de lactancia [Stillräumen] en el lugar de trabajo de la madre. Por último, durante el permiso de lactancia [Gewähnung der Stillzeit] la trabajadora no puede sufrir ninguna pérdida de ingresos [Verdienstausfall].

En el caso del trabajo a domicilio y similares, el mandante [Auftraggeber] o el subcontratista [Zwischenmeister] debe pagar a la trabajadora en período de lactancia el $75 \%$ de la media de su remuneración por hora [Stundenverdienst], con un mínimo establecido de 0,38E/hora al día.

Respecto a las horas extraordinarias [Mehrarbeit], tanto la mujer embarazada como en período de lactancia no puede trabajar ni horas extraordinarias, ni en turno de noche (entre las 20:00 h y las 6:00 h) ni domingos o festivos. Sin embargo, como excepción a la prohibición de empleo nocturno [Nachtarbeitsverbot], en Alemania las mujeres embarazadas pueden trabajar durante los cuatro primero meses de embarazo y del período de lactancia en el sector de la hostelería (hasta las 22:00 h), en el ordeño del ganado (a partir de las 5:00 h) o en el mundo del arte y de la música en exposiciones y actuaciones (hasta las 23:00 h).

\section{TERCER PÁRRAFO: DESPIDO [KÜNDIGUNG]}

El despido [Kündigung] de una mujer durante el período de embarazo y hasta cuatro meses después del parto se considera ilegal si el empresario conocía el estado de la mujer en el momento de despedirla. Por lo tanto, existe una prohibición de despido 
[Kündigungsverbot] que protege durante todo el periodo de embarazo a la trabajadora.

Por otra parte, si así lo desea, la trabajadora puede presentar su dimision al final del periodo de protección [Schutzfrist] después del parto. No obstante, si la relación laboral [Beschäftigungsverhältnis] de la mujer con la empresa se retoma en un período máximo de un año tras el parto, se considera que dicha relacion laboral no ha cesado. Sin embargo, si la mujer se reincorpora laboralmente a otra empresa [Wiedereinstellung] en el período de rescisión del contrato [Auflösung des Arbeitsverhältnisses], se considera que la relación laboral con la anterior empresa ha cesado $y$, por lo tanto, la trabajadora no conserva sus derechos sobre la relación laboral anteriormente establecida en el caso de que vuelva a la empresa.

\section{CUARTO PÁRRAFO: PRESTACIONES [LEISTUNGEN]}

Si la trabajadora no percibe el subsidio por maternidad [Mutterschaftsgeld] de acuerdo con las disposiciones del Código alemán de seguros sociales [Reichsversicherungsordnung] (en la actualidad, reemplazado en parte por la normativa del Sozialgesetzbuch), el empresario debe pagarle una cantidad media con respecto a su remuneración [Durchschnittsverdienst] de las últimas trece semanas o de los últimos tres meses de embarazo en el caso de que ésta haya tenido que dejar de trabajar por una prohibición de empleo parcial o total. Esto también se aplica si, debido a esta prohibición, el empleo o el tipo de salario [Entlohnungsart] de la trabajadora cambia.

En el caso de que se produzcan aumentos de sueldo [Verdiensterhöhungen] que no sean provisionales durante o después del periodo de liquidación, se parte del sueldo aumentado. Por el contrario, las reducciones de sueldo [Verdienstkürzungen] durante el periodo de liquidación a causa de una jornada reducida [Kurzarbeit], de incapacidad laboral [Arbeitsausfall] o de ausencias involuntarias en el trabajo [unverschuldete Arbeitsversäumnisse] no se tienen en cuenta en el cálculo de la remuneración.

Respecto a la prestación por maternidad, en este párrafo se establece que las mujeres que tengan contratado un seguro de 
enfermedad [gesetzliche Krankenkasse] reciban durante el periodo de protección y el día del parto [Entbindungstag] el subsidio por maternidad. No obstante, aunque la mujer no tenga contratado un seguro de enfermedad, si tiene un contrato laboral o si trabaja a domicilio en el momento en el que se inicia el periodo de protección, tiene derecho a recibir el subsidio por maternidad (máximo $210 €$, a fecha de 23 de octubre de 2012). En este caso, el subsidio por maternidad se percibe a través de la Oficina Federal de Seguros [Bundesversicherungsamt].

Las trabajadoras que tienen derecho a percibir el subsidio por maternidad reciben durante el periodo de protección y el día del parto una ayuda que asciende a la diferencia [Unterschiedsbetrag] entre $13 €$ (a fecha de 23 de octubre de 2012) y las deducciones obligatorias del salario [Arbeitsentgelt]. Si la relación laboral de la trabajadora con la empresa se rompe durante su embarazo o dentro del periodo de protección, ésta debe recibir el subsidio por maternidad de la autoridad competente [zuständige Stelle]. Este subsidio se suprime durante el periodo en el que las trabajadoras hacen uso del permiso por maternidad, de acuerdo con la Ley federal sobre prestaciones y permisos parentales [Bundeselterngeld- und Elternzeitgesetz], que será analizada más adelante.

Por otra parte, las trabajadoras que tienen contratado el seguro médico obligatorio [gesetzliche Krankenversicherung] reciben, además, las siguientes prestaciones por maternidad [Leistungen bei Schwangerschaft und Mutterschaft], de acuerdo con las disposiciones que aparecen en Libro V del Código de Seguridad Social [Fünftes Buch Sozialgesetzbuch]: asistencia médica [ärztliche Betreuung] y asistencia de una comadrona [Hebammenhilfe]; suministro de medicamentos, vendas y remedios terapéuticos [Heilmitteln]; parto hospitalario [stationäre Entbindung] y asistencia a domicilio [häusliche Pflege und Haushaltshilfe].

Por último, en este cuarto párrafo se precisa que el empresario debe dispensar a la trabajadora embarazada de acudir al puesto de trabajo cuando ésta deba someterse a reconocimientos médicos [Freistellung für Untersuchungen]. 


\section{QUINTO PÁRRAFO: APLICACIÓN DE LA LEY [DURCHFÜHRUNG DES GESETZES]}

En las empresas y administraciones [Betriebe und Verwaltungen] en las que más de tres mujeres trabajen de manera regular, debe haber una copia de esta ley a disposición de las empleadas en el lugar más adecuado (por ejemplo, colgada en una pared, distribuida entre las trabajadoras, etc.). En el caso de las trabajadoras a domicilio, debe haber una copia de esta ley en las habitaciones donde se realice el trabajo.

SEXTO PÁRRAFO: DELITOS E INFRACCIONES [STRAFTATEN UND ORDNUNGSWIDRIGKEITEN]

El empresario incurre en delito cuando infringe [zuwiderhandeln] alguna de las disposiciones de los párrafos anteriormente analizados. En Alemania, la infracción administrativa [Ordnungswidrigkeit] de esta ley puede conllevar una sanción [Geldbuße] de entre 2500 y 15000 euros. Además, se contempla que el empresario que, de forma intencionada, incurra en delito y con ello ponga en peligro la salud de la trabajadora o su capacidad productiva [Arbeitskraft], sea condenado hasta a un año de cárcel [Freiheitsstrafe] o reciba una multa [Geldstrafe] que puede alcanzar el importe de $180 €$ diarios [Tagessatz].

\subsubsection{VERORDNUNG ZUM SCHUTZE DER MÜTTER AM ARBEITSPLATZ [DECRETO PARA LA PROTECCIÓN DE LA MADRE EN EL TRABAJO]}

Este decreto ("MuSchArbV» de forma abreviada en alemán), que fue aprobado en 1997 y cuya última modificación se realizó en 2010, establece las medidas que deben llevarse a cabo en el lugar de trabajo para la mejora de la seguridad y de la protección de la salud [Gesundheitsschutz] de las trabajadoras embarazadas [schwangere Arbeitnehmerinnen], que hayan dado a luz recientemente [Wöchnerinnen] o que estén en período de lactancia [stillende Mütter].

En lo que a las condiciones de trabajo se refiere [Arbeitsbedingungen], el empresario debe valorar con la debida antelación cualquier actividad [Tätigkeit] que pueda poner en peligro la salud de las mujeres embarazadas o en periodo de lactancia por 
estar en contacto con sustancias peligrosas de origen químico o biologico [chemische und biologische Gefaltrstoffe] o con agentes nocivos fisicos [physikalische Schadfaktoren]. Esta valoración debe tener como objetivo evaluar los peligros para la trabajadora embarazada y las repercusiones [Auswirkungen] que pueden tener en su salud, así como determinar las medidas preventivas [Schutzmaß3nahmen] que deben tomarse.

Asimismo, el trabajador está obligado a informar a las mujeres embarazas o en periodo de lactancia, al resto de trabajadoras $y$, en el caso de que exista, al comité de empresa [Betriebsrat] y al comité de personal [Personalrat] sobre los resultados de la valoración de las medidas de seguridad y de protección de la salud en el lugar de trabajo [Arbeitsplatz].

Si esta valoración da como resultado que la seguridad o la salud de las trabajadoras embarazadas o en periodo de lactancia está en peligro, el empresario debe tomar las medidas necesarias para que, a través de una reforma temporal de las condiciones de trabajo $\mathrm{y}$, si fuera necesario, de la jornada laboral [Arbeitszeit], se descarte la posibilidad de que la mujer embarazada o en periodo de lactancia pueda exponerse a ningún riesgo para su salud o para la de su hijo. En el caso de que no pudieran llevarse a cabo los cambios en las condiciones laborales 0 en la jornada laboral de la trabajadora, el empresario debe tomar las medidas necesarias para que ésta disponga de un cambio de puesto de trabajo [Arbeitsplatzwechsel] temporal, siempre y cuando éste sea factible y justo.

$\mathrm{Al}$ igual que se vio anteriormente en la Mutterschutzgesetz, en este decreto se prohíbe el empleo de mujeres embarazadas o en periodo de lactancia en puestos de trabajo en los que el contacto con sustancias químicas, biológicas o agentes nocivos físicos puede poner en peligro la seguridad y la salud de la madre o del hijo. Igualmente, la prohibición de trabajar con agentes patógenos y con sustancias carcinógenas, mutagénicas [erbgutverändernd] o dañinas para el feto [fruchtschädigend] también forma parte de las limitaciones para el empleo [Beschäftigungsbeschränkungen] de las mujeres embarazadas o en periodo de lactancia. Por ello, se considera delito si el empresario 
da un trabajo de estas características a una mujer embarazada o en periodo de lactancia.

\subsection{LEYES LABORALES SOBRE LAS PRESTACIONES PARENTALES Y LOS SUBSIDIOS FAMILIARES}

\subsubsection{BUNDESELTERNGELD- UND ELTERNZEITGESETZ [LEY FEDERAL SOBRE PREST ACIONES Y PERMISOS PARENTALES]}

La Bundeselterngeld- und Elternzeitgesetz ("BEEG» de forma abreviada en alemán) es la ley que establece las prestaciones y los permisos parentales. Fue aprobada el 5 de diciembre de 2006 y posteriormente ha sido modificada el 15 de febrero de 2013.

A continuación, se procederá a analizar esta ley distinguiendo dos partes: la que trata sobre las prestaciones parentales y la que se ocupa de los permisos parentales.

\section{PÁRRAFO PRIMERO: PRESTACIONES PARENTALES [ELTERNGELD]}

Los beneficiarios [Berechtigte] de las prestaciones parentales son aquellas personas que tienen su domicilio o su residencia habitual en Alemania, viven con un niño a su cargo y no ejercen por completo o casi por completo alguna actividad profesional [Ervebstätigkeit]. También tienen derecho a disfrutar de estas prestaciones las personas que ostentan cargos públicos [im Dienst- oder Amtsverhältnisses stehen] destinados en el extranjero, los voluntarios en países en vías de desarrollo [Entwicklungshelfer] y los funcionarios del Estado que trabajan en el extranjero de acuerdo con las orientaciones para el desplazamiento de trabajadores [Entsenderechtlinien]. En el caso de los hijos adoptivos [angenommene Kinder], los padres tienen derecho a recibir las prestaciones parentales a contar desde el día de la adopción.

Si los padres no pueden hacerse cargo de sus hijos por enfermedad, por minusvalía grave o por fallecimiento, los parientes hasta el tercer grado de consanguinidad [Verwandte bis zum dritten 
Grad] que se hagan cargo de ellos tienen derecho a percibir las prestaciones parentales.

Respecto a los extranjeros que trabajan en Alemania, los que tienen libertad de circulación [freizügigkeitsberechtigte Ausländer] tienen derecho a recibir las prestaciones si poseen un permiso de residencia permanente [Niederlassungserlaubnis] o un permiso de residencia [Aufenthaltserlaubnis] que les autorice a desarrollar su actividad profesional en Alemania.

Otra cuestión que se aborda en este primer párrafo es el importe de las prestaciones parentales. Se concede el $67 \%$ del sueldo de la actividad profesional antes del nacimiento del hijo, con un máximo de $1800 €$ (a fecha de 15 de febrero de 2013) al mes por cada mes completo en el que el beneficiario no ha percibido el sueldo de la actividad profesional desempeñada. La cantidad mịnima establecida para las prestaciones parentales en Alemania es de $300 €$ (a fecha de 15 de febrero de 2013). No obstante, en el caso de que ya haya dos o más niños en la unidad familiar, a esta cifra se le suma la «bonificación por hermanos" [Geschwisterbonus], que supone un 10\% más (al menos, 75 $€)$. De la misma forma, en el caso de parto múltiple [Mehrlingsgeburt], las prestaciones parentales se elevan hasta los $300 €$ a partir del segundo hijo y por cada uno de los que nazcan después de éste en el parto.

En el caso de las personas que desempeñan un trabajo por cuenta ajena [nichtselbstständige Erwerbstätigkeit], la renta se determina a partir de los doce meses naturales [Kalendermonate] previos al nacimiento del niño. Sin embargo, si el trabajo en cuestión es por cuenta propia [selbstständige Erverbstätigkeit], la renta se determina a partir de los respectivos periodos de cálculo de beneficios fiscales [steuerliche Gewinnermittlungszeiträume], basados en el último periodo impositivo [Veranlagungszeitraum] antes del nacimiento del niño.

Aparte del importe por prestaciones parentales, se pueden percibir otras ayudas de manera simultánea; por ejemplo, las prestaciones por maternidad [Mutterschaftsleistungen], determinados subsidios [Zuschüsse] a los que tienen derecho los funcionarios e incluso prestaciones que se perciben en otro país, en el caso de los 
beneficiarios alemanes que viven fuera de Alemania y que tienen derecho a percibir también prestaciones en su país de residencia.

Respecto al periodo de referencia [Bezugszeitraum], las prestaciones parentales se perciben desde el día del nacimiento hasta que el niño cumple los catorce meses. En el caso de los hijos adoptivos, los padres pueden percibir las prestaciones parentales desde el momento de la adopción hasta que el niño cumple ocho años. En todos los casos, la prestación se percibe a través de importes mensuales [Monatsbeträge], hasta un total de doce. No obstante, uno de los padres [ein Elternteil] puede percibir prestaciones parentales durante un periodo de tiempo de dos a doce meses. Este periodo puede extenderse hasta los catorce meses si se le rebaja el sueldo a uno de los progenitores, lo que puede poner en peligro el bienestar del niño. Si ambos progenitores cumplen los requisitos correspondientes, deberán decidir qué importes mensuales de esta prestación recibe cada uno.

Por último, cabe destacar que tanto las prestaciones parentales como otras parecidas se enmarcan dentro del conjunto de las prestaciones sociales [Sozialleistungen].

PÁRRAFO SEGUNDO: EL PERMISO PARENTAL [ELTERNZEIT]

Para poder optar al permiso parental, la trabajadora (o el trabajador) debe vivir con su hijo, con un hijo adoptivo o con un niño en acogimiento familiar [Vollzeitpflege] en un mismo hogar. También tienen derecho a disfrutar de este permiso los trabajadores que vivan con sus nietos, siempre y cuando estén a su cargo y los eduquen, ya sea porque uno de los progenitores es menor de edad [minderjährig] o porque comenzase una formación profesional antes de cumplir los 18 años.

El permiso parental se prolonga hasta que el niño cumple tres años. No obstante, si son varios hijos, se prevé un permiso parental por cada uno de ellos. La versatilidad es grande, ya que, con la aprobación del empresario, existe incluso la posibilidad de disfrutar de una parte del permiso parental (doce meses máximos) en cualquier momento hasta que el niño cumpla ocho años. En el caso de hijos adoptivos, en acogimiento familiar o en acogimiento preadoptivo [Adoptionspflege], el permiso parental puede disfrutarse hasta tres años 
a partir del acogimiento del niño, con posibilidad de extenderlo, como máximo, hasta que éste cumpla ocho años. En todos estos casos tanto la madre como el padre pueden disfrutar del permiso parental. Sin embargo, los trabajadores no pueden ejercer ninguna actividad remunerada [erwerbstätig sein] de más de treinta horas semanales [Wochenstunden] durante el permiso parental. Asimismo, en el caso de que tengan problemas de incompatibilidad, pueden solicitar una reducción de la jomada laboral [Verringerung der Arbeitszeit], que se revoca una vez que haya finalizado el permiso.

Para poder solicitar un permiso parental, es necesario que el beneficiario avise por escrito (con un mínimo de siete semanas de antelacion) al empresario y le especifique durante qué periodo dentro de los dos años de que dispone quiere disfrutar del permiso. Si es la madre la que solicita el permiso, existe la posibilidad de solaparlo con el periodo de protección de protección por maternidad [Mutterschutzfrist]. Igualmente, es posible tanto extender como finalizar antes de tiempo el permiso parental, siempre y cuando el empresario esté de acuerdo.

Al igual que en otras leyes que hemos visto, también existe en ésta una cláusula para la protección contra el despido [Kündigungsschutz], mediante la cual se prohíbe al empresario que despida al trabajador en las ocho semanas anteriores al permiso parental y en el periodo en el que éste se disfruta. Por lo tanto, el empresario solo puede despedir al trabajador una vez finalizado el permiso parental y si respeta el periodo de preaviso [Kündigungsfrist], de tres meses.

Por último, esta ley contempla que se hagan contratos temporales [befristete Arbeitsverträge] a los trabajadores que se contraten para la sustitución [Vertretung] de otros empleados que no puedan trabajar durante el periodo de prohibición de empleo, por permiso parental o por una excedencia [Arbeitsfreistellung].

\subsubsection{BUNDESKINDERGELDGESETZ [LEY FEDERAL DE SUBSIDIOS FAMILIARES]}

La Bundeskindergeldgesetz («BKGG» de forma abreviada en alemán) es la ley que establece los subsidios familiares en Alemania, válidos solo para aquellas personas que tienen la modalidad de obligación 
real de contribuir (frente a los que tienen la obligación personal). Fue aprobada el 11 de octubre de 1995 y posteriormente ha sido modificada en dos ocasiones: el 28 de enero de 2009 y el 7 de mayo de 2013.

Según esta ley, los beneficiarios del subsidio familiar [Kindergeld] deben tener su domicilio o su residencia habitual [gewöhnlicher Aufenthalt] en Alemania. Como dato a destacar, a diferencia de otros subsidios, éste puede ser percibido directamente por los hijos en el caso de que sean huérfanos de padre y de madre [Vollwaise].

En el caso de los extranjeros que no tienen libertad de circulación, se estipula que solo reciban el subsidio familiar los que posean un permiso de residencia permanente o un permiso de residencia con el fin de ejercer una actividad profesional. También los alemanes que vivan en el extranjero pero que tengan la obligación real de contribuir [unbeschränkt einkommensteuerpflichtig] tienen derecho a percibirlo.

Para poder recibir esta ayuda, no es necesario que haya un vínculo directo con el niño, ya que dentro de la consideración de hijos se incluyen los adoptivos, los niños acogidos [Pflegekinder] e incluso los nietos. En el caso de los hijos mayores de 18 años, entrarán en consideración siempre y cuando no hayan cumplido los 21 años, no tengan un empleo y estén inscritos en Alemania en la Agencia Federal de Empleo alemana [Agentur für Arbeit] como personas que buscan empleo [Arbeitssuchender]. Respecto a los mayores de 21 años pero menores de 25 , se contempla que perciban este subsidio si se están formando para ejercer una profesión determinada o si no pueden continuar con una formación profesional [Berufsausbildung] por falta de plazas. En el caso de haber finalizado una primera formación profesional o unos estudios de enseñanza superior [Erststudium], solo se concederá el subsidio si el hijo no ejerce ninguna actividad profesional remunerada, a excepción de las actividades profesionales que no superen las 20 horas semanales o similares.

Respecto a la cuantía del subsidio familiar, no existe una cantidad fija, sino que depende del número de hijos que tenga el beneficiario. Así, a fecha de 7 de mayo de 2013, la suma por el primer y por el segundo hijo asciende a 184 euros mensuales; para el tercer hijo, 190 
euros mensuales, y para el cuarto hijo y los siguientes, 215 euros mensuales.

Por último, en esta ley se especifica que se puede conceder por cada hijo el subsidio familiar, el complemento de asignación por hijos a cargo [Kinderzuschlag] y las prestaciones para la educación y la participación [Leistungen für Bildung und Teilhabe] de manera simultánea, a diferencia de otras prestaciones que son incompatibles con este subsidio, como la asignación por hijos a cargo [Kinderzulage]. Puesto que las prestaciones mencionadas comparten muchos puntos en común y pueden llegar a confundirse, procederemos a continuación a caracterizar el Kinderzuschlag y las Leistungen für Bildung und Teilhabe.

\section{KINDERZUSCHLAG}

El complemento de asignacion por hijos a cargo [Kinderzuschlag] es una prestacion familiar muy importante en Alemania, ya que ayuda a familias con rentas bajas y combate la pobreza infantil. Tiene como beneficiarios a los padres que viven con hijos solteros y menores de 25 años en la misma unidad familiar. Para estar en condiciones de percibirla, es imprescindible que también se perciba el subsidio familiar [Kindergeld] $\mathrm{u}$ otras prestaciones similares. Asimismo, es necesario que los ingresos mínimos de la unidad familiar sean de 900 euros para las unidades familiares con dos progenitores y de 600 euros para las unidades familiares con un núcleo familiar monoparental [alleinerziehend]. No obstante, es necesario que tanto los ingresos como el patrimonio [Vermögen] no superen los umbrales máximos establecidos.

Respecto a la cuantía, esta ayuda asciende a $140 €$ máximos al mes por cada hijo (a fecha de 7 de mayo de 2013), que se suman a la cuantía por el subsidio familiar (184 $€$ ), por lo que la ayuda total ascendería a $324 €$. No obstante, la cuantía del complemento puede disminuir con el tiempo si las condiciones de los ingresos o del patrimonio de la unidad familiar se ven alteradas. 


\section{LEISTUNGEN FÜR BILDUNG UND TEILHABE}

Las prestaciones para la educación y la participación [Leistungen fuir Bildung und Teilhabe] se enmarcan dentro de las prestaciones de protección social. Para estar en condiciones de solicitar esta ayuda, es imprescindible que también se perciba el subsidio familiar [Kindergeld] $\mathrm{u}$ otras prestaciones similares, incluida la de las ayudas a la vivienda [Wohngeld].

El objetivo principal de esta ayuda es satisfacer las necesidades de los niños en el ámbito escolar. Para ello, esta ayuda cubre los gastos relacionados con las excursiones escolares de un día, el transporte escolar y los almuerzos en el colegio o en la guardería, entre otros. Asimismo, dependiendo del Estado federado, los jóvenes de entre 18 y 25 años que estén estudiando o recibiendo una formación también pueden percibir esta ayuda, siempre y cuando no perciban ningún sueldo durante el periodo de formación [Ausbildungsvergütung].

\section{LA CONCILIACIÓN ENTRE LA VIDA FAMILIAR Y LA VIDA LABORAL}

\subsection{INTRODUCCIÓN}

El concepto de conciliación entre la vida familiar y la vida laboral [Vereinbarkeit von Familie und Beruf] está intrínsecamente relacionado con todas las prestaciones y ayudas familiares que hemos analizado hasta ahora. De hecho, es un concepto muy arraigado en la cultura alemana y su importancia se refleja en muchos estudios y encuestas.

Este concepto viene recogido por primera vez en un apartado del Libro III del Código de Seguridad Social alemán [Sozialgesetzbuch, Drittes Buch], en el que se establece que las contribuciones del activo fomento del trabajo [Arbeitsförderung] deben tener en cuenta las condiciones de vida [Lebensverhältnisse] de mujeres y hombres, que pueden tener niños o parientes a su cargo. No obstante, esta conciliación no solo permite establecer y proteger los lazos familiares entre los miembros de una unidad familiar, sino también fomentar el 
asesoramiento y ayuda a aquellas personas que se reincorporan al trabajo [Berufrrickkehrende] tras un periodo de tiempo considerable.

De esta forma, la conciliación entre la vida familiar y la vida laboral se ha convertido en uno de las herramientas más importantes en lo que a la competencia entre empresas se refiere, ya que todas quieren ofrecer las condiciones más favorables posibles para conseguir atraer la atención de trabajadores cualificados [Fachkräfte] con familia.

Por último, cabe destacar que ya no son solamente las mujeres las que intentan conciliar su vida familiar con la laboral, sino que cada vez más hombres valoran la oportunidad de poder participar activamente en la vida familiar. En definitiva, favorecer a las familias [Familienfreundlichkeit] influye positivamente tanto en la contratación [Rekrutierung] por parte de empresas de trabajadores cualificados muy solicitados como en la relación entre los trabajadores y la propia empresa.

\subsection{MEDIDAS PARA LA IMPLANTACIÓN}

La conciliación familiar se apoya sobre una serie de medidas que deben llevarse a cabo para asegurar su cumplimiento. Estas medidas se aplican tanto en las grandes empresas como en las pequeñas y medianas. En el caso de estas dos últimas, se pone especial hincapié en el apoyo al cuidado de los hijos [Kinderbetreuung] a través de la facilitación de plazas reservadas [Belegplätze] en guarderías y de ayudas económicas para este fin. Para ello, la flexibilidad de los horarios de trabajo es indispensable. En este aspecto, destacan sobre todo las pequeñas empresas, que ofrecen soluciones individuales para cada empleado.

Todo este apoyo al empleado influye de manera positiva en el funcionamiento de la empresa. Por ejemplo, en numerosos estudios se ha demostrado que la selección de personal [Personalauswahl] de muchas empresas ha mejorado a raíz de la aplicación de medidas de conciliación, gracias a las cuales han conseguido más solicitudes por parte de candidatos [Bewerber] más cualificados. Asimismo, se está 
consiguiendo reducir el absentismo [Fehlzeit] por causas familiares en el lugar de trabajo, ya que los trabajadores tienen la posibilidad de reducir sus faltas si su empresa ha implantado medidas para promover la conciliación.

Si bien la implantación de medidas que favorecen a la conciliación pueden conllevar algún gasto, también conllevan, simultáneamente, una reducción de los costes [Kosteneinsparung] de la empresa, ya que las ayudas a la reinserción laboral [Wiedereinstiegshilfen] durante o tras un permiso parental fomentan el desarrollo de competencias como el trabajo en equipo [Teamfähigkeit] o la capacidad organizativa [Organisationstalent], a menudo adquiridas únicamente a través de la impartición de costosos seminarios.

Puesto que cada empresa tiene una cultura empresarial distinta [Unternehmenskultur], las medidas que se lleven a cabo para la conciliación deben adaptarse a cada una de ellas. No obstante, será más fácil implantar medidas para favorecer la conciliación en empresas que fomenten la jornada laboral reducida [reduzierte Arbeitszeiten] y el ascenso de trabajadores que sean madres y padres a cargos de dirección [Führungspositionen].

En el caso de las empresas en las que aún no se hayan implantado medidas para la conciliación, los trabajadores tienen la posibilidad de hacer constar su necesidad de apoyo [Unterstützungsbedarf] de diferentes formas; por ejemplo, durante las entrevistas de desempeño [Mitarbeitergespräche] o a través de encuestas rellenadas por los empleados, siempre y cuando se haya informado previamente de ello a los representantes de los trabajadores [Arbeitnehmervertretung].

\subsection{POSIBILIDADES DE FINANCIACIÓN Y PROMOCIÓN}

Si el encargado decide implantar medidas para la conciliación en su empresa, lo primero que debe hacer es ponerse en contacto con los organismos pertinentes para saber si existe alguna posibilidad de financiación [Fördermöglichkeit] para la implantación de tales medidas en su empresa. 
En el caso de las personas que se reincorporan al trabajo tras haber internumpido su actividad profesional o su formación interna [betriebliche Berufsausbildung] para dedicarse al cuidado de los hijos, se prevén para ellas prestaciones para el fomento del empleo [Arbeitsforderung] y para su formación profesional continua [Weiterbildung].

En cada estado federado se llevan a cabo diferentes programas para conseguir estos objetivos. Por ejemplo, en Baja Sajonia existe el programa Förderung der Integration von Frauen in den Arbeitsmarkt (FIFA), que tiene como objetivo mejorar las condiciones laborales de las mujeres y la conciliación entre la vida familiar y la vida laboral de las trabajadoras. También hasta el año 2015 se llevará a cabo el programa Förderung von Maßnahmen zur Verbesserung der Vereinbarkeit von Beruf und Familie, cuyo objetivo es implantar medidas para la conciliación.

Sin embargo, cabe señalar que existe una restricción en la elección de los ámbitos de actuación en los que están medidas se pueden llevar a cabo. En el caso de las pequeñas y medianas empresas, las medidas que más se aplican son las que tienen que ver con la distribución de los permisos parentales y del apoyo al cuidado de los hijos y de parientes. Por lo tanto, para llevar a cabo medidas más amplias, es necesaria la cooperación de directivos [Führungskräfte] y de responsables de personal [Personalverantwortliche] que involucren al resto de los trabajadores a través de proyectos y talleres.

Esta implicación por parte de las empresas no tiene únicamente como fin la instauración de medidas conciliadoras, sino también la mejora de su funcionamiento y del rendimiento de los trabajadores. Por ello, durante los periodos de permisos parentales, se intenta que el trabajador siga teniendo una conexión con la empresa ofreciéndole un trabajo a tiempo parcial [Teilzeitbeschäftigung] o cursos de formación profesional continua.

También en el caso del apoyo a los trabajadores con niños se persigue el mismo objetivo. Como la instalación de guarderías [Kinderbetreuungsplätze] en el lugar de trabajo puede ser muy cara para las pequeñas y medianas empresas, éstas ponen a disposición de los 
padres con hijos un determinado número de plazas reservadas en guarderías [Krippen], centros de preescolar [Kindergärten] y guarderías para niños en edad escolar [Horten für Schulkinder], para cuyo pago reciben ayudas económicas. Asimismo, en algunas ocasiones, las empresas ponen a disposición de los padres a niñeras profesionales [Tagesmutter] que cuidan a grupos de un máximo de cinco niños en sus propias casas. Con la aplicación de todas estas medidas para facilitar a los padres la conciliación entre su trabajo y el cuidado de sus hijos, los encargados de las empresas reciben subsidios y quedan exentos de pagar impuestos.

En el caso de que surja alguna emergencia relacionada con el niño (por ejemplo, que enferme o que la guardería a la que asista no esté disponible por alguna causa), la empresa les ofrece a los padres la posibilidad de trabajar puntualmente desde casa [von zuhause arbeiten] (si su cargo se lo permite). Si la empresa dispone de una habitación habilitada para que los padres puedan estar con sus hijos [Eltern-KindZimmer], se les permite llevárselos al lugar de trabajo, siempre y cuando sea por poco tiempo. Sin embargo, si el niño está enfermo durante varios días y es menor de 12 años, el trabajador puede hacer uso de su licencia por asuntos propios [Sonderurlaub], que consta de 10 días no remunerados por año. No obstante, esta cifra puede aumentar a 25 días por año en el caso de tener más de dos hijos, y a 50 días por año en el caso de tratarse de una familia monoparental.

Aparte de los empresarios y de las organizaciones interprofesionales [Branchenverbände], existen otros contactos [Ansprechpartner] en lo que al tema de la compatibilidad del trabajo con el cuidado de los niños se refiere, como los Landesjugendämter (en español, "oficinas centrales de menores»), los Estados federados, etc.

\section{EL PANORAMA EUROPEO: LA POLÍTICA FAMILIAR EN LA UNIÓN EUROPEA}

La política familiar de la Unión Europea hace especial hincapié en la igualdad laboral y en las prestaciones familiares. Por ello, se considera que todas estas directivas, incluso las más antiguas, están 
encaminadas a alcanzar la conciliación entre la vida laboral y la vida familiar.

Basándonos en los puntos tratados anteriormente en este trabajo, hemos escogido varias directivas europeas a modo de muestra $y$ las hemos clasificado en los dos siguientes grupos:

o directivas europeas sobre la igualdad entre hombres y mujeres y

o directivas europeas sobre la protección de la mujer embarazada en el ámbito laboral y sobre los permisos parentales.

En cada uno de los grupos se detallará en qué consiste cada directiva y se facilitará su nombre tanto en español como en alemán.

\subsection{DIRECTIVAS EUROPEAS SOBRE LA IGUALDAD ENTRE HOMBRES Y MUJERES}

\section{a. Directiva 79///CEE (Richtlinie 79/7/EWG)}

A través de esta directiva se garantiza el cumplimiento del principio de igualdad [Grundsatz der Gleichbehandlung] entre hombres y mujeres en el acceso al empleo [Zugang zur Beschäftigung], a la formación [Berufbbildung] y a la promoción profesional. El marco de aplicación es la seguridad social, por lo que también se garantiza que el trabajador o la trabajadora estén protegidos contra los riesgos de accidentes de trabajo [Arbeitsunfall], de enfermedad profesional y de paro, entre otros.

El principio de igualdad al que se hace mención en la directiva asegura la eliminación de la discriminación por sexo y ofrece al ciudadano la posibilidad de recurrir a la vía jurisdiccional en el caso de que considere que haya sido perjudicado por la violación de dicho principio. No obstante, los Estados miembros pueden excluir del ámbito de aplicación del principio de igualdad las prestaciones tras períodos de interrupción de empleo [Beschäftigungsunterbrechung] y la edad de jubilación [Rentenalter], entre otros. Por lo tanto, son los Estados miembros los que establecen en última instancia las disposiciones necesarias para ajustarse a esta directiva. 
Tras la publicación de esta directiva, la Comisión dio a los Estados Miembros un plazo máximo de seis años para adoptarla y de siete años para enviar los datos respecto a dicha adopción, con el fin de que pudiera ser revisada por la Comisión.

\section{b. Directiva 2006/54/CE (Richtlinie 2006/54/EG)}

La finalidad de esta directiva es garantizar la aplicación del principio de igualdad anteriormente mencionado en el ámbito laboral. Para alcanzar este objetivo, propone que se fomente la promoción profesional y que se mejoren las condiciones de trabajo.

Esta directiva entra en profundidad en la definición de los límites del principio de igualdad. Para ello, propone una serie de definiciones de conceptos clave en el tema como "discriminación directa/indirecta" [unmittelbare/mittelbare Diskriminierung], "acoso" [Belästigung], "retribución» [Entgelt] o "regímenes profesionales de seguridad social" [betriebliche Systeme der sozialen Sicherheit]. Entre estos conceptos, el de la prohibición de la discriminación [Diskriminierungsverbot] es el más recurrente dentro de esta directiva. Esta prohibición se aplica tanto a la discriminación en el ámbito de las retribuciones como en el de las prestaciones. De esta manera, está prohibido que el empresario interrumpa el mantenimiento o la adquisición de derechos de la trabajadora durante los periodos de descanso por maternidad [Mutterschaftsurlaub] o por razones familiares [Urlaub aus familiären Gründen].

En el ámbito del acceso al empleo, se establece que no se puede ejercer ningún tipo de discriminación en los criterios de selección [Auswahlkriterien] $\mathrm{ni}$ en las condiciones de contratación [Einstellungsbedingungen]. Tampoco se podrá dar ningún tipo de discriminación en el acceso a la orientación profesional [Berufsberatung], a la formación profesional en cualquier nivel, al reciclaje profesional [Umschulung] o a la experiencia laboral práctica [praktische Berufserfahrung].

Respecto al ámbito de los permisos parentales, esta directiva es compatible con cualquier derecho que los Estados miembros reconozcan de forma específica y única en su territorio. No obstante, los Estados están obligados a garantizar que tanto tras el permiso de 
maternidad como tras el de paternidad o el de adopción [Adoptionsurlaub], los padres tendrán derecho a reincorporarse a su
puesto de trabajo o a uno equivalente.

El principio de igualdad no se aplica únicamente a los trabajadores activos, sino también a los que estén de baja por enfermedad o en paro involuntario [unverschuldete Arbeitslosigkeit] y a los funcionarios [Beamte]. Sin embargo, no se aplica, entre otros, a los contratos individuales [Einzelverträge] de los trabajadores autónomos [Selbstständige] o a los contratos de seguro [Versicherungsverträge] en los que no participe el empresario, en el caso de los trabajadores por cuenta ajena [abhängig Beschäftigte].

Para asegurar la aplicación del principio de igualdad, se prevén indemnizaciones para aquellos trabajadores que sufran discriminación en el lugar de trabajo así como sanciones para las empresas que incumplan dicho principio.

\section{c. Directiva 2010/41/UE (Richtlinie 2010/41/EU)}

Esta directiva es una ampliación de la Directiva 2006/54/CE, ya que se ubica dentro del ámbito laboral, pero se centra en la aplicación del principio de igualdad en el ejercicio de la actividad autónoma. En definitiva, su objetivo es aplicar el principio de igualdad de trato en aquellos ámbitos que no están cubiertos por las dos directivas anteriormente comentadas.

Desde el punto de vista de las prohibiciones de discriminación, en esta directiva se destaca la eliminación de la discriminación tanto en el sector público [öffentlicher Sektor] como en el privado [privater Sektor] en relación con la creación y la ampliación de empresas o de cualquier otra forma de actividad autónoma [selbstständige Tätigkeit]. Por otra parte, se fomentan iniciativas de actividad empresarial [unternehmerische Initiativen] entre mujeres y entre cónyuges o parejas de hecho que quieran constituir una sociedad. Tanto las mujeres como los cónyuges o parejas de hecho tendrán también derecho a sustituciones temporales [befristete Vertretung] en el caso de que las necesiten para poder disfrutar de un permiso parental. 
Al igual que en las dos otras directivas, en esta también se contempla que el trabajador reciba una indemnización si sufre discriminacion en el lugar de trabajo.

\subsection{DIRECTIVAS EUROPEAS SOBRE LA PROTECCIÓN DE LA MUJER EMBARAZADA EN EL ÁMBITO LABORAL $Y$ SOBRE LOS PERMISOS PARENTALES}

\section{a. Directiva 92/85/CEE (Richtlinie 92/85/EWG)}

Esta directiva (modificada por última vez en junio de 2007) tiene como objetivo promover la implantación de medidas que ayuden a mejorar la seguridad y la salud en el trabajo de la mujer embarazada, que haya dado a luz recientemente o en periodo de lactancia.

El eje central de esta directiva es el estado de la mujer embarazada en el ámbito laboral. Por ello, se contempla en todos los casos que se tomen las medidas necesarias para asegurar la higiene y protección de las trabajadoras en el lugar de trabajo, así como para controlar las cargas físicas [körperliche Ermüdung] o mentales [geistige Ermüdung] que puedan afectar negativamente a su salud o a la de su hijo.

Aparte de las disposiciones generales de protección de la trabajadora, se establece la prohibición de que la trabajadora embarazada realice cualquier actividad que le suponga un riesgo de exposición. Igualmente, se contemplan una serie de medidas para evitar que las mujeres embarazadas se vean obligadas a desempeñar un trabajo nocturno [Nachtarbeit] como, por ejemplo, trasladarlas a un trabajo diurno [Arbeitsplatz mit Tagarbeit] de forma temporal o incluso darles la posibilidad de obtener una dispensa de trabajo [Beurlaubung] o una prolongación del permiso de maternidad cuando dicho traslado no sea posible.

Respecto al permiso de maternidad, esta directiva establece que la trabajadora disfrute de un periodo mínimo de catorce semanas distribuidas antes y/o después del parto. Tanto durante el periodo de embarazo como durante el del permiso, estará prohibido despedir a la trabajadora, salvo casos excepcionales que no estén relacionados con 
su estado y previa justificación del empresario de los motivos del despedido [Kündigungsgnünde] por escrito. De la misma manera, la trabajadora tiene derecho durante el permiso de maternidad a recibir una prestación adecuada conforme a los ingresos que tendría si continuase ejerciendo su actividad laboral.

Por último, al final de esta directiva se adjuntan dos anexos en los que se recogen diversos agentes, procedimientos y condiciones de trabajo que pueden influir negativamente en la salud de la trabajadora, del feto o del hijo recién nacido y que, por lo tanto, el empresario debe tener en cuenta.

\section{b. Directioa 2010/18/UE (Richtlinie 2010/18/EU)}

En esta directiva se revisa el Acuerdo marco sobre el permiso parental, en el que se establecen los requisitos mínimos sobre el permiso parental. Dicho acuerdo se aplica tanto a hombres como a mujeres que tengan un contrato de trabajo o una relación laboral de cualquier tipo, incluidos los de carácter parcial, de duración determinada o los que se tienen con una empresa de trabajo temporal [Leiharbeitsunternehmen].

Respecto a las condiciones del permiso parental, a través del Acuerdo se establece que los trabajadores tienen derecho a disfrutar de un permiso parental [Eltermurlaub] por nacimiento o por adopción de un hijo para cuidarlo hasta que cumpla ocho años. Su duración mínima ha de ser de cuatro meses. Por lo demás, a partir del cumplimiento mínimo de las disposiciones del Acuerdo, cada uno de los Estados miembros puede definir las condiciones y normas de aplicación del permiso parental en su territorio.

\section{CONCLUSIONES}

Tal y como hemos analizado a lo largo de este trabajo, la mejora de las condiciones de vida de la sociedad alemana se han llevado a cabo a través de la implantación de prestaciones, permisos y subsidios familiares. Estos conceptos tienen una gran presencia en la cultura alemana y han dado lugar a un rico acervo terminológico en este tema. Esto se debe a que lo que en principio eran conceptos 
meramente burocráticos han pasado a ser parte de la vida cotidiana alemana y se han convertido en un pilar fundamental para el Estado de bienestar en este país.

Es precisamente el hecho de que estos conceptos se hayan asimilado dentro de la cultura alemana lo que hace que, en muchas ocasiones, su traducción sea muy compleja, ya que algunos términos tienen una gran carga cultural y no ofrecen una correspondencia ni total ni aproximada en la cultura española.

Para poder explicar las diferencias terminologicas entre el alemán y el español en éste y en cualquier campo, es necesario tener en cuenta tanto el factor cultural como el lingüístico. El alemán se caracteriza por ser una lengua que presenta una gran tendencia a la formación de unidades léxicas a través de la composición y de la sufijación, que dan lugar a la estructuras complejas que requieren el uso de traducciones explicativas cuando queremos trasladarlas al español. Por lo tanto, para clasificar los términos obtenidos del análisis comparativo que hemos realizado, es necesario tener en cuenta las características idiosincrásicas de cada lengua.

Tras extraer y confrontar los términos escogidos con su traducción en español, podemos establecer dos grados de correspondencia entre los términos en alemán y su traducción en español:

- Correspondencia total. En este caso, hacemos referencia a aquellos términos en alemán que tienen un equivalente en español. A menudo, se trata de términos del

lenguaje común. Por ejemplo, Hebamme ("comadrona»), Frühgeburt ("parto prematuro") o Mehrlingsgeburt ("parto múltiple») pertenecen a esta categoría.

- No existe correspondencia. El término en alemán no tiene una correspondencia directa en español, pero es traducible. En este caso, la mejor opción es realizar una traducción explicativa, como hemos comprobado que se ha efectuado en muchos casos en documentos de la Unión Europea. De esta forma, términos como Wöchnerin o Geschwisterbonus deben traducirse al español haciendo uso de una explicación en la que se refleja de la forma más precisa posible todos los 
aspectos que entraña esa palabra. En el caso de Wöchnerin, hay que precisar que se trata de una mujer que ha dado a luz recientemente (no basta con traducir el término como "que ha dado a luz", ya que, como se ha visto, el factor temporal influye a la hora de percibir determinadas prestaciones $y$ permisos). Igualmente, al traducir el término Geschwisterbonus como «bonificación por hermanos», es recomendable aportar datos sobre la cuantía y el número de hermanos a partir de la cual se aplica dicha bonificación.

Aparte de estas dos categorías, podríamos establecer una tercera que no atiende a la correspondencia lingüística, sino a la inexistencia del concepto en la cultura meta. En estos casos también se suele acudir a la traducción explicativa, ya que intentar asemejar el concepto a otro en la cultura meta daría como resultado una traducción poco fidedigna y confusa. Existen muchos ejemplos de esta categoría dentro del análisis efectuado, especialmente, en la parte de los subsidios por hijo a cargo, ya que el sistema alemán de prestaciones sociales difiere mucho en este punto del español. Así, si bien términos como Kinderzuschlag o Kindergeld no existen en el sistema de prestaciones españoles, a través de una traducción explicativa podemos darle al lector español una idea aproximada del concepto. En el caso de Kinderzuschlag, será imprescindible especificar que este tipo de subsidio es un complemento de asignación por hijos a cargo y no un subsidio familiar en sí, a diferencia del Kindergeld. Por lo tanto, en los casos en los que el concepto cultural no exista, será necesario reflejar sus relaciones con otros conceptos a fin de que el lector pueda comprender lo mejor posible el término en cuestión.

Finalmente, queremos hacer hincapié en que este trabajo solo es, debido a su limitada extensión, una muestra de la terminología que se emplea en este campo, por lo que recogemos la que consideramos básica o fundamental, pues se trata de los conceptos clave que funcionan como descriptores de las leyes a las que nos referimos. Sin embargo, por ser un campo de gran interés para el estudio de la terminología comparada y la terminografía jurídica del alemán y el español, creemos que este trabajo puede constituir el embrión de otro más extenso en el que se recopile un mayor número de términos y se 
estudien de forma contrastada aspectos como las características de la formación léxica.

\section{REFERENCIAS BIBLIOGRÁFICAS}

\section{Fuentes bibliográficas}

ALLGEMEINES GLEICHBEHANDLUNGSGESETZ (AGG), de 14 de agosto de 2006, Bundesgesetzblatt I, pág. 1897, modificada por última vez mediante el artículo 8 de la ley del 3 de abril de 2013, Bundesgesetzblatt I, pág. 610. Bundesministerium der Justiz [información al ciudadano en línea], <http://www.gesetze-im-internet.de/bundesrecht/agg/gesamt.pdf> [Consulta: 12 de octubre de 2014]

BUNDESKINDERGELDGESETZ (BKGG), de 11 de octubre de 1995, Bundesgesetzblatt I, págs. 142, 3177, modificada por última vez mediante el artículo 3 de la ley del 7 de mayo de 2013, Bundesgesetzblatt I, pág. 1167. Bundesministerium der Justiz [información al ciudadano en línea], $<$ http://www.gesetze-im-

internet.de/bundesrecht/bkgg_1996/gesamt.pdf> [Consulta: 9 de octubre de 2014]

GESETZ ZUM ELTERNGELD UND ZUR ELTERNZEIT (BUNDESELTERNGELD- UND ELTERNZEITGESETZ - BEEG), de 5 de diciembre de 2006, Bundesgesetzblatt I, pág. 2748 , modificada por última vez mediante el artículo 1 de la ley del 25 de febrero de 2013, Bundesgesetzblatt I, pág. 254. Bundesministerium der Justiz [información al ciudadano en línea], <http://goo.gl/hoim3> [Consulta: 12 de octubre de 2014]

GESETZ ZUM SCHUTZ DER ERIVERBSTÄTIGEN MUTTER (MUTTERSCHUTZGESETZ MuSCHG), de 24 de enero de 1952, Bundesgesetzblatt I, pág. 2318, modificada por última vez mediante el artículo 6 de la ley del 23 de octubre de 2012, Bundesgesetzblatt I, pág. 2246. Bundesministerium der Justiz [información al ciudadano en línea], <http://goo.gl/ys88k> [Consulta: 12 de octubre de 2014]

GESETZ ZUR GLEICHSTELLUNG VON FRAUEN UND MÄNNERN IN DER BUNDESVERWALTUNG UND IN DEN GERICHTEN DES BUNDES (BUNDESGLEICHSTELLUNGSGESETZ - BGLEIG), de 30 de noviembre de 2001, Bundesgesetzblatt I, pág. 3234, modificada por última vez mediante el artículo 15 del párrafo 54 de la ley del 5 de febrero de 2009, Bundesgesetzblatt I, pág. 160. Bundesministerium der Justiz [información al ciudadano en línea], <http://goo.gl/uZcDZ> [Consulta: 15 de octubre de 2014]

VEREINBARKEIT VON FAMILIE UND BERUF, parágrafo 8 del artículo primero del 
Sozialgesetzbuch (SGB), Drittes Buch (III), de 24 de marzo de 1997 Bundesgesetzblatt l, págs. 594-595, modificada por última vez mediante el articulo 9 de la ley del 17 de junio de 2013, Bundesgesetzblatt I, págs. 1555. 1556. Bundesministerium der Justiz [información al ciudadano en línea], shttp://www.gesetze-im-intemet.de/sgb_3/> [Consulta: 13 de octubre de 2014]

VERORDNUNG ZUM SCHUTZE DER MUTTER AM ARBEITSPLATZ, de 15 de abril de 1997, Bundesgesetzblatt I, pág. 782, modificada por última vez mediante el artículo 5, párrafo $\$$ del decreto del 26 de noviembre de 2010, Bundesgesetzblatt I, pag. 1643. Bundesministerium der Justiz [información al ciudadano en línea], <http://www.gesetze-iminternet.de/bundesrecht/muscharbv/gesamt.pdf> [Consulta: 12 de actubre de 2014]

BUNDESMNISTERIM FÚR FAMILE, SENTOREN, FRAUEN UND JUGEND. Elterngeld und Elternzeit. Das Bundeselterngeld- und Elternzeitgesetz [en línea]. Aschaffenburgo, mayo 2012, <http://goo.gl/W8VYq> [Consulta realizada el 10 de octubre de 2014]

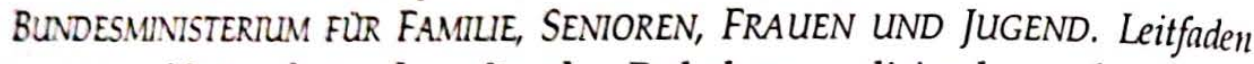
zum Mutterschutz [en línea]. Paderborn, diciembre de 2012, <http://goo.gl/RAR2R> [Consulta: 10 de octubre de 2014]

BUNDESZENTRALAMT FÜR STEUERN (2013). Merkblatt Kindergeld [en línea], <http:// wiww.arbeitsagentur.de/zentraler-

Content/Veroeffentlichungen/Merkblatt-Sammlung/MB-

Kindergeld.pdf> [Consulta: 11 de octubre de 2014]

BLNDESMINISTERILM FÜR WIRTSCHAFT UND TECHNOLOGIE. Fachkräfte sichern. Vereinbarkeit oon Familie und Beruf [en línea]. Berlín, febrero de 2012, < http://tinvurl.com/nwu719w > [Consulta realizada el 9 de octubre de 2014]

DIRECTIVA 79//CEE DEL CONSEJO DE LAS COMUNIDADES EUROPEAS, DE 19 DE DICIEMBRE DE 1978, RELATIVA A LA APLICACIÓN PROGRESIVA DEL PRINCIPIO DE IGUALDAD DE TRATO ENTRE HOMBRES Y MUJERES EN MATERIA DE SEGURIDAD SOCIAL, Diario Oficial de las Comunidades Europeas, 10 de enero de 1979, $\mathrm{n}^{\circ} \quad \mathrm{L}$ 6/24, págs. 174-175, <http://eur-lex.europa.eu/legalcontent/ES/TXT/?uri=CELEX:31979L0007> [Consulta: 13 de octubre de 2014]

DIRECTIVA 92/85/CEE DEL CONSEJO, DE 19 DE OCTUBRE DE 1992, RELATIVA A LA APLICACIÓN DE MEDIDAS PARA PROMOVER LA MEJORA DE LA SEGURIDAD Y DE LA SALLD EN EL TRABAJO DE LA TRABAJADORA EMBARAZADA, QUE HAYA DADO A LUZ O EN PERIODO DE LACTANCIA. Diario Oficial de las Comunidades Europeas, 28 de noviembre de 1992, n. ${ }^{\circ}$ L 348, págs. 1-7, <http://goo.gl/EJXt9> [Consulta: 12 de octubre de 2014]

DIRECTIVA 2006/54/CE DEL PARLAMENTO EUROPEO Y DEL CONSEJO, DE 5 DE JULIO 
DE 2006, RELATIVA A LA APLICACION DEL PRINCIPIO DE IGUALDAD DE OPORTUNIDADES E IGUALDAD DE TRATO ENTRE HOMBRES $Y$ MUIERES EN ASUNTOS DE EMPLEO Y OCUPACIÓN. Diario Oficial de la Unión Europea, 26 de junio de $2006 \mathrm{n}^{\circ} \mathrm{L}$ 204, págs. 32-36, <http://eurlex.europa.eu/LexUriServ/LexUriServ.do?uri=OJ:L:2006:204:0023:0036:es: PDF> [Consulta: 12 de octubre de 2014]

DIRECTIVA 2010/18/UE DEL CONSEJO, DE 8 DE MARZO DE 2010, POR LA QUE SE APLICA EL ACUERDO MARCO REVISADO SOBRE EL PERMISO PARENTAL, celebrado por BUSINESSEUROPE, la UEAPME, el CEEP y la CES, y se deroga la Directiva 96/34/CE. Diario Oficial de la Unión Europea, 18 de marzo de 2010, n. ${ }^{\circ}$ L 68, págs. 13-20, <http://is.gd/barbDm> [Consulta: 12 de octubre de 2014]

DIRECTIVA 2010/41/UE DEL PARLAMENTO EUROPEO Y DEL CONSEJO, DE 7 DE JULIO DE 2010, SOBRE LA APLICACIÓN DEL PRINCIPIO DE IGUALDAD DE TRATO ENTRE HOMBRES Y MUJERES QUE EJERCEN UNA ACTIVIDAD AUTÓNOMA, Y POR LA QUE SE DEROGA LA DIRECTIVA 86/6113/CEE DEL CONSEJO. Diario Oficial de la Unión Europea, n. ${ }^{\circ}$ L 180, págs. 1-6, <http://goo.gl/bGhpR> [Consulta: 11 de octubre de 2014]

MINISTERIO DE EMPLEO Y SEGURIDAD SOCIAL (2013). Prestaciones familiares [en línea]. <http://goo.gl/SFcLl5>. [Consulta: 15 de octubre de 2014]

STATISTISCHES BUNDESAMT. Vereinbarkeit von Familie und Beruf. Ergebnisse des Mikrozensus 2011 [en línea]. Wiesbaden, 2012, <https://www.destatis.de/DE/Publikationen/WirtschaftStatistik/Bevoel kerung/Verein barkeitFamilieBeruf_122012.pdf?_blob=publicationFile> [Consulta: 15 de octubre de 2014]

Obras de consulta

ALONSO-OLEA GARCÍA, Belén (2001): La igualdad entre hombres y mujeres y de género en la Unión Europea [en línea], <http://goo.gl/h7phf> [Consulta: 15 de octubre de 2014]

ARUFE VARELA, Alberto (2008): La igualdad de mujeres y hombres en Alemania. Estudio comparado de la legislación alemana con la legislación española y traducción castellana [en línea], <http://numrl.com/igualdaddelasmujeresyhombresenalemania> [Consulta: 15 de octubre de 2014]

CASTRO García, Carmen; PAzOS MORÁn, María (2007): Permisos de maternidad, paternidad y parentales en Europa: algunos elementos para el análisis de la situación actual [en línea]. Instituto de Estudios Fiscales, $<$ http://www.ief.es/documentos/recursos/publicaciones/papeles_trabaj o/2007_26.pdf > [Consulta: 15 de octubre de 2014]

EUR-LEX. El acceso al Derecho de la Unión Europea [en línea], <http://eurlex.europa.eu/es/index.htm> [Consulta: 120 de octubre de 2014] 
Ley 4/995, de 23 de marzo de 1995, de regulación del permiso maternidad. Boletín Oficial del Estado, 24 de marzo de 1995,

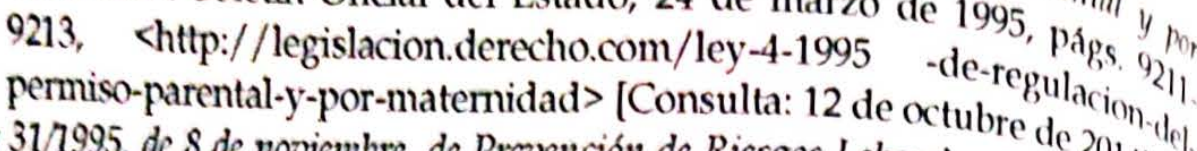
Ley 31/7995, de 8 de noxiembre, de Prevención de Riesgos Laborales. Bolete $201_{4}$ del Estado, 10 de noviembre de 1995, págs. 32590 Of $\mathrm{fi}_{\mathrm{i}}$

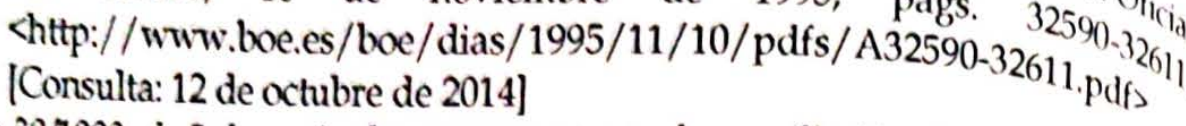

Ley 39/1999, de 5 de noviembre, para promover la conciliación de la vida familiar.
laboral de las personas trabajadoras. Boletín Oficial del Estado, 6 . noviembre de 1999, pags. 38934-38942, <http://goo.gl/HqAJV> [C ${ }_{0}{ }_{\text {nul }}$ de
13 de octubre de 2014]

Ley Orgánica 3/2007, de 22 de marzo, para la igualdad efectiva de mujeres y holmbres Boletín Oficial del Estado. Boletín Oficial del Estado, 23 de marzo de 2007 , págs. 12611.12645, <http://www.boe.es/buscar/doc.php?id=BOE.A.
2007-6115> [Consulta: 9 de octubre de 2014] Real Decreto 295/2009, de 6 de marzo, por el que se regulan las prestaciones
económicas del sistema de la Seguridad Social por maternidad, paternidad, riesgo
durante el embarazo y riesgo durante la lactancia natural. Boletín Oficiol durante el embarazo y riesgo durante la lactancia natural. Boletín Oficial del Estado, 21 de marzo de 2009, págs. 27936-27981,
<http://www.boe.es/diario_boe/txt.php?id=BOE-A-2009-4724> [Consulta: 12 de octubre de 2014]

FUNDACOÓN REDMADRE (2012). Politicas de apoyo a la maternidad, breve estudio comparation en los paises de la UE [en línea]. Madrid. http://tinyurl.com/ns5zlyq > [Consulta: 14 de octubre de 2014]

IATE. INTERACTIVE TERMINOLOGY FOR EUROPE. <http://iate.europa.eu> [Consulta: 20 de junio de 2013].

NÚNEZ-CORTÉS CONTRERAS, Pilar (2002): La licencia por maternidad de la trabajadora [en línea]. Madrid: Editorial Dykinson,
<http://numrlcom/113408> [Consulta: 14 de octubre de 2014]

RENATE, Beck; SEBALD, Andrea; WINTERMANN, Katja (2011): Vereinbarkeit von Familie und Führungspositionen - Karriereknick? [en línea]. Págs. 16-27, <http://www.bayernde/Anlage10352105/Recherchearbeit\%20Vereinbar keit\%20von \%20Familie\%20und\%20Beruf.pdf> [Consulta: 11 de octubre de 2014]

SERRANO-DOLADER, David (1996): Del rothaarig alemán al pelirrojo español: un caso de diversidad morfológica [en línea], < http://dehesa.unex.es:8080/xmlui/handle/10662/1707 > [Consulta: 9 de junio de 2014] 